\title{
Effects of the Metal Salts on the Staining of Elastic Fibers with Hematein
}

\author{
By \\ Masumi AKITA, Seong Ho LEE* and Katsuji KANEKO \\ First Department of Anatomy, Saitama Medical School, Saitama 350-04, Japan \\ *Kongju National Junior College, Korea \\ -Received for Publication, July 12, $1987-$ \\ Key words: Hematein, Elastic fibers, Elastin, Metal salts, Stain \\ Summary: The effects of various metal salts on the staining of elastic fibers with hematein \\ were tested at light and electron microscopic levels. \\ Potassium tungustate and sodium molybdate were effective at light and electron microscopic \\ levels. Ammonium metavanadate, stannous chloride, potassium tellurate and uranyl acetate \\ moderately stained elastic fibers at light microscopic level. However, these metal salts, except \\ stannous chloride, did not show the marked enhancement of the electron density of elastin. \\ Stannous chloride moderately enhanced the electron density of elastin. \\ It was suggested that hematein is capable of binding to elastin and subsequently or simulta- \\ neously chelating metal ions which render the elastin electom opaque.
}

It has been known that hematoxylin has an affinity for elastic fibers (Pizżolato and Lillie, 1969. Lillie et al., 1974), and hematoxylin enhances the electron density of elastic fibers (Brissie et al., 1974).

We found that hematein, which is an oxidation product of hematoxylin, exhibited stronger affinity for elastic fibers than hematoxylin, at pHs near neutrality. Furthermore, the affinity of hematein for elastic fibers was enhanced by metal salts such as tungustate and molybdate (Kaneko and Akita, 1977a, 1977b, 1978).

In this study, the effects of various metal salts on the staining of elastic fibers with hematein were tested at light and electron microscopic levels.

\section{Materials and Methods}

Specimens from rabbit aorta were fixed in $10 \%$ formalin, Zenker-formalin or Bouin's fluid and cut in paraffin at a thickness of $5 \mu \mathrm{m}$.

Hematein was prepared according to the method of Arshid et al. (1954). Fifty milligram of hematein were dissolved in $50 \mathrm{ml}$ of $0.1 \mathrm{M}$ phosphate buffer $(\mathrm{pH}$ 7.0 ), and then added $50 \mathrm{mg}$ of metal salts. The metal salts used in this study were listed in Table 1, according to Pizzolato and Lillie (1967).

Deparaffinized sections were stained with the staining solutions for $\mathbf{3 0}$ minutes.

For electron microscopy, specimens from rabbit aorta were fixed in $2 \%$ glutaraldehyde and post-fixed in $\mathrm{OsO}_{4}$. Specimens were 
Table 1. Effects of metal salts on staining of elastic fibers. with hematein

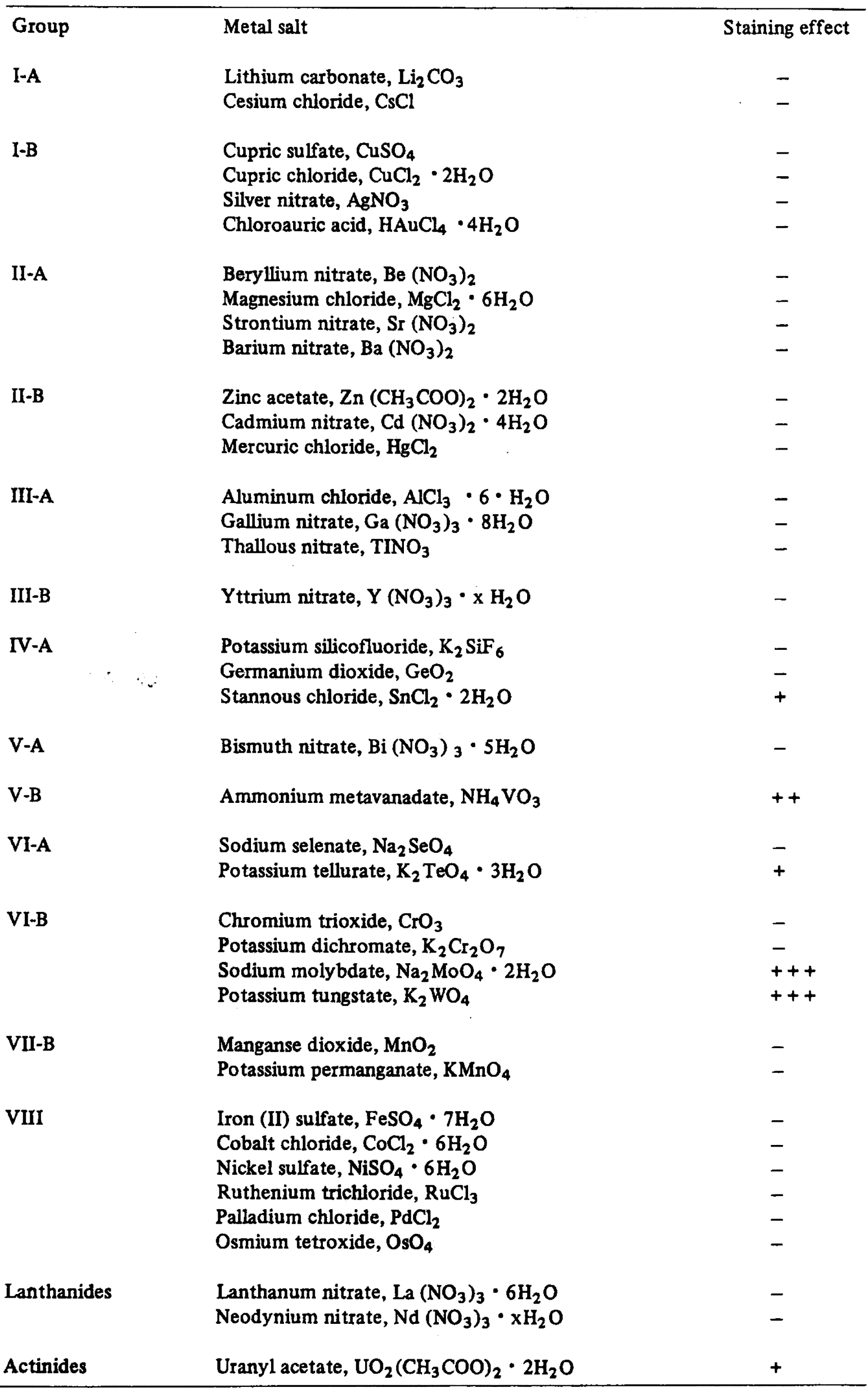

-$, no change, Increasing of staining was indicated as + (slight $)$ and $+++($ extreme $)$. 
dehydrated through graded ethanol and embedded in epoxy resin. Ultrathin sections mounted on copper grids were stained for 5 to 10 minutes with the staining solutions, which exhibited positive staining reaction at light microscopic level, and followed by uranyl acetate and lead citrate.

\section{Results}

\section{Light microscopy}

Elastic fibers were strongly stained with potassium tungstate and sodium molybdate (Fig. 1, 2). Ammonium metavanadate and uranyl acetate showed moderate affinity for elastic fibers (Fig. 3, 4). Elastic fibers were slightly stained with stannous chloride and potassium tellurate. These results were summarized in Table 1.

\section{Electron microscopy}

Elastic fibers consist of central amorphous components (elastin) and microfibrils. Elastin was electron-microscopically trancelucent in the tissue sections treated with uranyl acetate and lead citrate. The electron density of elastin was slightly increased by hematein, tungustate or molybdate, respectively. It was markedly enhanced by molybdate-hematein and tungustate-hematein followed by uranyl acetate and lead citrate (Fig. 5, 6). Siannous chloride moderately enhanced the density of elastin, and nuclei and cytoplasm were strongly enhanced the electron density (Fig. 7). Potassium tellurate, ammonium metavanadate and uranyl acetate slightly enhanced the electron density of elastin.

\section{Discussion}

Heavy metals were used for increasing contrast of tissue sections in the electron microscopy (Watson, 1958a. b). Heavy metals tested in his works were as follows; uranyl acetate, phosphotungustic and phosphomolybdic acids, sodium uranate, lead acetate, barium hydroxide and lead hydroxide. Among several heavy metals tested including lead monoxide (Karnovsky, 1961), lead citrate (Raynolds, 1963), potassium permanganate (Lawn, 1960. Sutton, 1968), chromyl chloride (Bullivant and Hotchin, 1960), uranyl acetate and lead citrate have been widely used. However, elastin, which was an amorphous component of elastic fibers, showed no affinity for cationic stains such as uranyl acetate or lead citrate applied to tissues that have been routinly prepared for electron microscopy as described by Raynolds (1963). Elastin had a marked affinity to phosphotungstic acid (Pearse and Molinari, 1960. Paule, 1963. Greenlee et al., 1966). Silicotungustic acid also enhanced the electron density of elastin (Yoshihama et al., 1986).

In this study, tungustate and molybdate were effective at light and electron microscopic levels. Ammonium metavanadate, stannous chloride, potassium tellurate and uranyl acetate moderately stained elastic fibers at light microscopic level. However, these metal salts, except stannous chloride, did not show the marked enhancement of the electron density of elastin. Palladium chloride and hematein did not stain elastic fibers at light microscopic level. However, Morris et al. (1978) reported that palladium chloride followed by lead citrate was useful for electron stain for elastin. Vanadyl sulfate and vanadyl sulfate-ammonium hepta-molybdate mixture were used for electron stain, but no mention was made of elastin (Callaham and Horner, 1964).

At light microscopic level, we reported that hematein showed stronger affinity to elastic fibers than hematoxylin and the affinity was markedly enhanced by adding metal salts (Kaneko and Akita, 1977a, $1977 \mathrm{~b}, 1978)$. The mode of elastic fibers staining by unmordanted hematoxylin and 
hematein remains obscure. Lillie et al. (1974) suggested that hematoxylin binds to tyrosine or possible desmosine content of elastin on a speculative basis, from the blocking by nitrations. Horobin and James (1970) proposed that elastin staining, generally, occurred by large dye molecule adhesion by van der Waals forces. Brissie et al. (1974) reported that hydrogen bonding assumed to be responsible for staining of leastin. In contrast with these findings, there is no single mechanism covering all elastin staining (Lillie and Hullmer, 1976). We previously reported that hematein and metal salt-complex binds to elastin by both hydrogen and ionic bonds (Kaneko and Akita, 1977b). It was suggested that complex organic molecules, such as hematoxylin and hematein, are capable of binding to elastin and subsequently or simultaneously chelating metal ions which render the elastin electron opaque. The nature of the group in elastin binding with hematein and metal salt-complex has not been determined. Further studies are needed to determine the nature of the group might account for this staining.

\section{References}

1) Arshid, F.M., Desai, J.N., Duff, D.J., Giles, C.H., Jain, S.K. and Macneal, I.R.: A study of certain natural dyes. I. The adsorption of brazilwood and logwood colouring matters by fibres. J.Soc. Dyers Colourists, 70: 392-401, 1954.

2) Brissie, R.M., Spicer, S.S., Hall, B.J. and Thompson, N.T.: Ultrastructural staining of thin sections with iron hematoxylin.

J. Histochem. Cytochem., 22: 895-907, 1974.

3) Bullivant, S. and Hotchin, J.: Chromyl chloride, a new stain for electron microscopy. Exp. Cell Res., 21: 211-214, 1960.

4) Callaham, W.P. and Horner J.A.: The use of vanadium as a stain for electron microscopy. J. Cell Biol., 20: 350-356, 1964.
5) Greenlee, T.K., Ross, R. and Hartman, J.L.: The fine structure of elastic fibers. J.Cell Biol., 30: 59-71, 1966.

6) Horobin, R.W. and James, N.T.: The staining of leastic fibers with direct blue 152. General hypothesis for the staining of elastic fibers. Histochemie, 22: 324-336, 1970.

7) Kaneko, K. and Akita, M.: On the histological applications, especially through the stains for mucosubstances, elastic fibers and collagenous fibers, of the hematein based on the method of Arshid et al. Acta Anat. Nipponica, 52: 173-181, 1977a. (in Japanese with English summary)

8) Kaneko, K. and Akita, M.: On elastic fibers stain with hematein and its staining mechanism. Okajimas Folia. Anat. Jpn., 54: 187194, $1977 \mathrm{~b}$.

9) Kaneko, K. and Akita, M.: On the staining of elastic fibers with alum hematoxylins. Stain Technol., 53: 43-45, 1978.

10) Karnovsky, M.J.: Simple methods for "staining with lead" at high $\mathrm{pH}$ in electron microscopy. J. Biophys. Bioehem. Cytol., 11: 729-732, 1961.

11) Lawn, A.M.: The use of potassium permanganate as an electron-dense stain for sections of tissue embedded in epoxy resin. J. Biophys. Biochem. Cytol., 7: 197-198, 1960.

12) Lillie, R.D., Pizzolato, P. and Donaldson, P.T.: The Clara hematoxylin reaction. Acta. Histochem., 49: 204-219, 1974.

13) Lillie, R.D. and Hullmer, H.M.: Histopathologic Technic and Practical Histochemistry. 4th Ed. p. 708, McGraw-Hill, Inc., New York, 1976.

14) Morris, S.M., Stone, P.J., Rosenkrans, W.A., Calore, J.D., Albright, J.T. and Franzblau, C.: Palladium chloride as a stain for elastin at the ultrastructural level. J. Histochem. Cytochem., 26: 635-644, 1978.

15) Paule, W.J.: Electron microscopy of the newborn rat aorta. J. Ultrastruc. Res., 8: 219-235, 1963.

16) Pease, D.C. and Molinari, S.: Electron microscopy of muscular arteries: pial vessels of the cat and monkey. J. Ultrastruc. Res., 3: 447 468, 1960.

17) Pizzolato, P. and Lillie, R.D.: Metal saltshematoxylin staining of skin keratohyalin granules. J. Histochem. Cytochem., 15: 104-119, 1967.

18) Pizzolato, P. and Lillie R.D.: Schiff and hematoxylin reactions of mammalian arterial elastica. Arch. Pathol., 88: 581-583, 1969. 
19) Reynolds, E.S.: The use of lead citrate at high $\mathrm{pH}$ as an electron-opaque stain in electron microscopy. J. Cell Biol., 17: 208$211,1963$.

20) Sutton, J.S.: Potassium permanganate staining of ultrathin sections for electron microscopy. J. Ultrastruc. Res., 21: 424-429, 1968.

21) Watson M.L.: Staining of tissue sections for electron microscopy with heavy metals. J. Biophys. Biochem. Cytol., 4: 475-478, 1958.
22) Watson, M.L.: Staining of tissue sections for electron microscopy with heavy metals. II. Application of solutions containing lead and barium J. Biophys. Biochem. Cytol., 4: 727-730, 1958.

23) Yoshihama, I., Asuwa, N., Masuda, S., Watanabe, Y. and Otaka, Y.: A novel section staining for electron microscopic demonstration of elastic fibers using silicotungstic acid. Connective Tissue, 18: 95-103, 1986 (in Japanese with English summary) 


\section{Explanation of Figures}

\section{Plate I}

Fig. 1. Potassium tungustate and hematein stain. Rabbit aorta. $\times 200$

Fig. 2. Sodium molybdate and hematein stain. Rabbit aorta. $\times 200$

Fig. 3. Ammonium metavanadate and hematein stain. Rabbit aorta $\times 200$

Fig. 4. Uranyl acetate and hematein stain. Rabbit aorta. $\times 200$ 

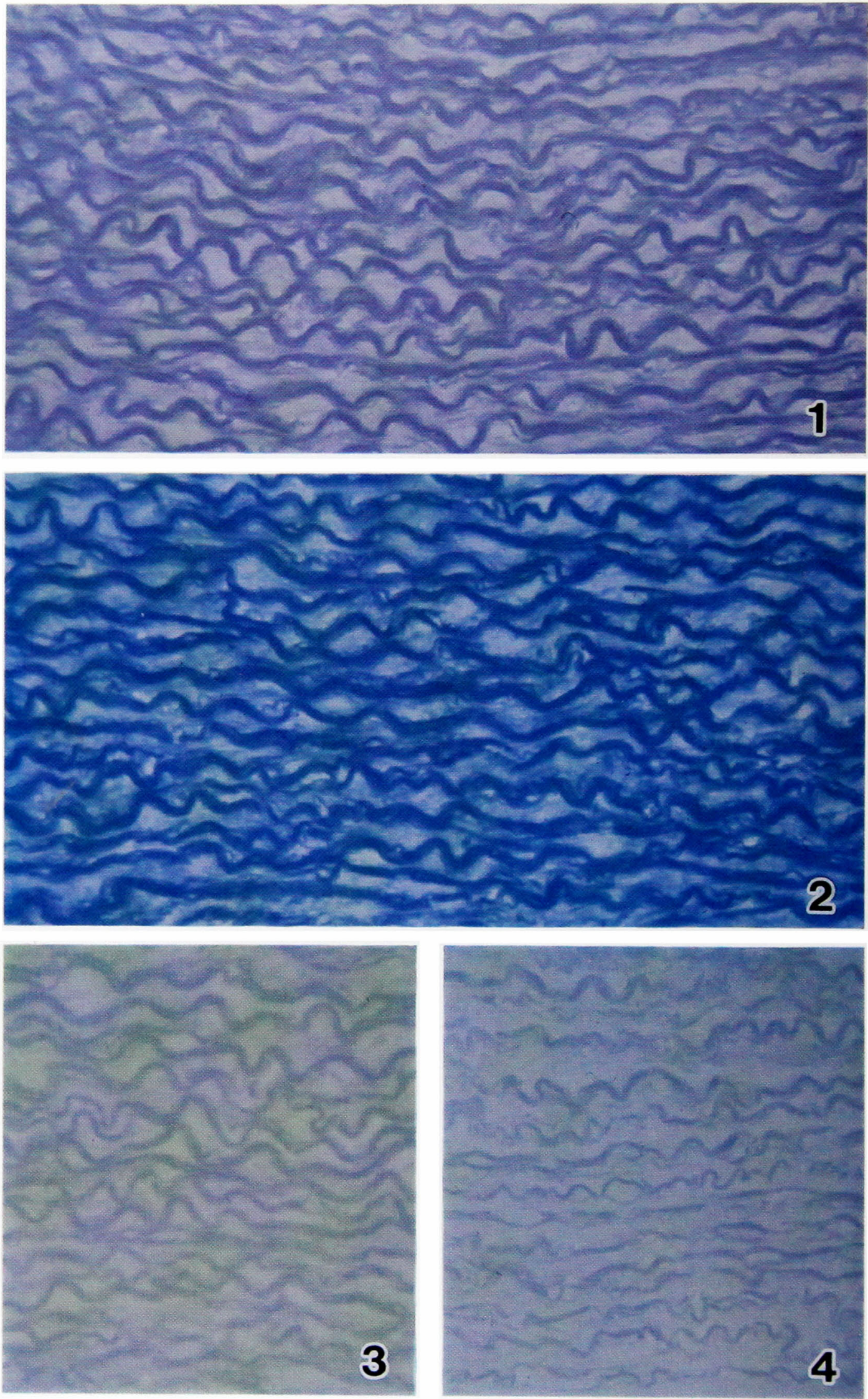


\section{Plate II}

Fig. 5. Sodium molybdate and hematein stain, followed by uranyl acetate and lead citrate. Rabbit aorta. Elastin $=$ asterisks, $\times 12,000$

Fig. 6. Potassium tungustate and hematein stain, followed by uranyl acetate and lead citrate. Rabbit aorta. Elastin $=$ asterisks, $\times 12,000$

Fig. 7. Stannous chloride and hematein stain, followed by uranyl acetate and lead citrate. Rabbit aorta. Elastin $=$ asterisks, $\times 21,000$ 


\section{Plate II}

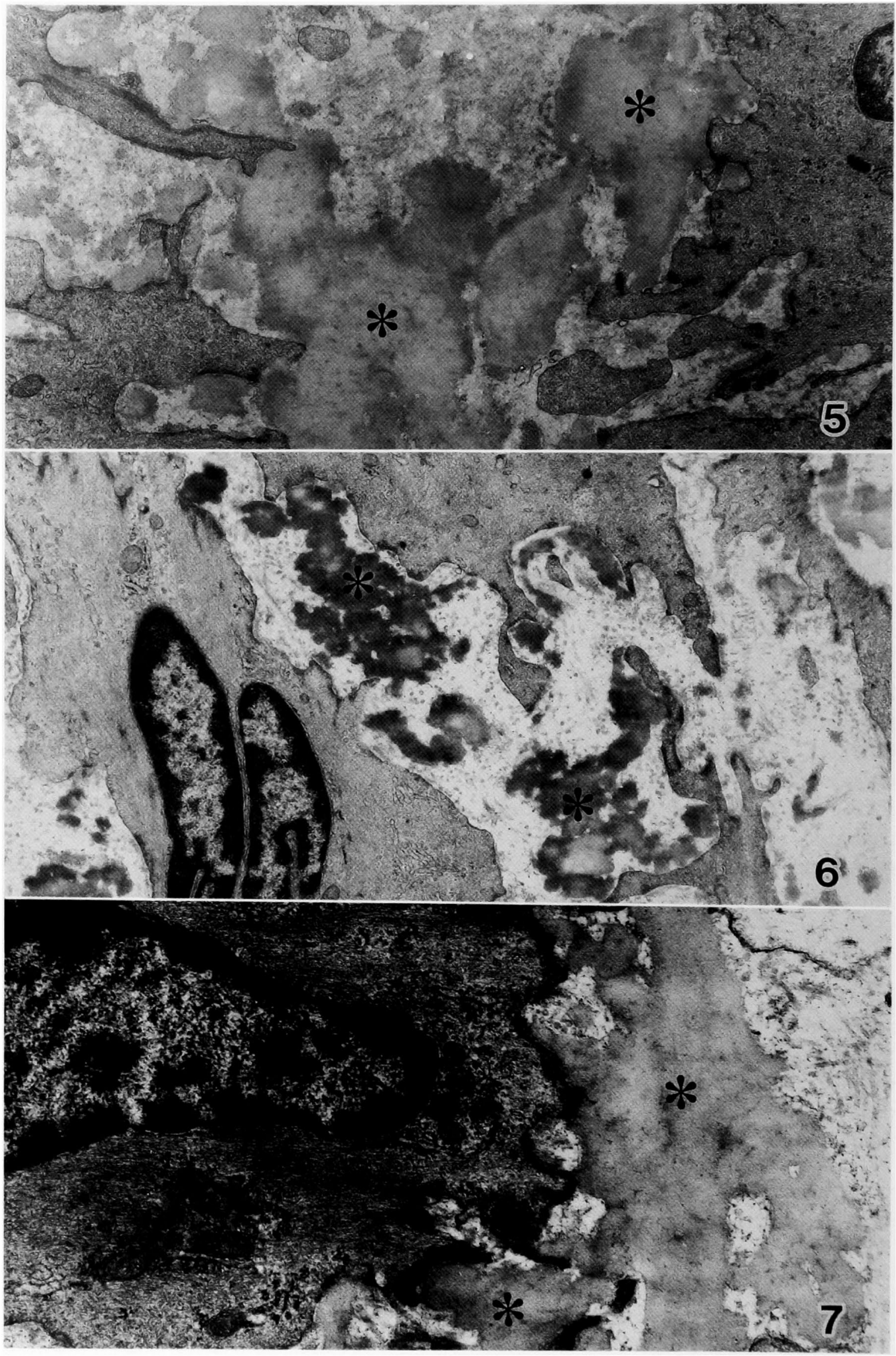

